\title{
РЕЙТИНГ ГОРОДСКИХ КАДАСТРОВЫХ КВАРТАЛОВ ЗОНЫ ЗАСТРОЙКИ МНОГОЭТАЖНЫМИ ЖИЛЫМИ ДОМАМИ
}

\author{
${ }^{1}$ Кудряшова А. И., ${ }^{1}$ Мазуркин П.М. \\ ${ }^{1}$ ФББОУ ВПО «Поволжсский государственный технологический университет». Россия, \\ Республика Марий Эл, 424000, г. Йошкар-Ола, пл. Ленина, д. 3. e-mail: Little- \\ one7@yandex.ru; kaf_po@mail.ru
}

По классификации ООН среди 11 классов почвенного покрова первые три составляют травяной покров, древесно-кустарниковая растительность и леса. В городе им соответствуют три элемента растительного покрова: газоны, древесные насаждения (древостои) и кустарник обычный. Для выявления статистических закономерностей было принято зонирование городской застройки. Картографическими измерениями в ГИС «Карта 2011» г. Йошкар-Ола была выделена «жилая зона», а в ней «Зона застройки многоэтажными жилыми домами (58 кадастровых кварталов)». Рассмотрены параметры элементов растительного покрова: количество элементов разного уровня, площадь и периметр, коэффициенты абсолютной и относительной формы, а также активности растительности. Получены двухчленные уравнения ранговых распределений, проведен рейтинг и выбран лучший кадастровый квартал по экологическим условиям.

Ключевые слова: город, жилая зона, кадастровые квартала, растительный покров, распределения, закономерности, рейтинг, лучший квартал.

\section{A RATING OF CADASTRAL BLOCKS FOR URBAN AREAS CONSTRUCTION OF MULTI-STOREY RESIDENTIAL BUILDINGS}

\author{
${ }^{1}$ Kudryashova A. I., ${ }^{1}$ Mazurkin P. M. \\ ${ }^{1}$ Volga state technological University. 3, Lenin sq. Republic of Mari El, Yoshkar-Ola, \\ 424000, Russia.e-mail: Little-one7@yandex.ru; kaf_po@mail.ru
}

According to UN classification among 11 classes of soil cover the first three are grass, trees and shrubs and forests. In the city they correspond to the three elements of vegetation: lawns, tree plantings (trees) and shrub normal. To identify statistical regularities were adopted zoning for city-building. Map dimensions in GIS "Map 2011" Yoshkar-Ola was allocated to "residential zone" and "Area of construction of multi-storey residential buildings (cadastral 58 quart crystals)". The parameters of the elements of the vegetation cover: the number of elements of different levels, area and perimeter, the absolute and relative form, and activity of vegetation. The obtained equations binomial rank distributions, conducted the ratings and selected the best of cadastral quarter on environmental conditions.

Key words: town, residential area, cadastral quarter, land cover, distribution, patterns, rating, best quarter.

По мнению Мэтью Смита [9], «умный» город просто неизбежно будет экологически устойчивым. Такой город не расходует попусту энергию на освещение и отопление. Система умных парковок сокращает выбросы выхлопных газов автомобилей. Датчики предупредят коммунальные службы о неполадках в водопроводной или газовой сети, когда те ещё только назревают. Система управления дорожным движением «умного города» не только создаст «зелёную волну» для кареты «скорой помощи», но и передаст в больницу все данные по пациенту ещё до того, как его доставят, экономя время и спасая жизнь. Для нашей статьи применим девиз «Умный - значит зелёный». 
По классификации ООН [10] среди 11 классов почвенного покрова первые три составляют: травяной покров, древесно-кустарниковая растительность и леса. В городе им соответствуют три элемента растительного покрова: газоны, кустарник обычный и древесные насаждения (древостои). Для выявления закономерностей было принято зонирование городской застройки, и картографическими измерениями в ГИС «Карта 2011» была выделена зона 1 «жилая зона», а в ней подзона 11 «Зона застройки многоэтажными жилыми домами (58 кадастровых кварталов)» (рис. 1).

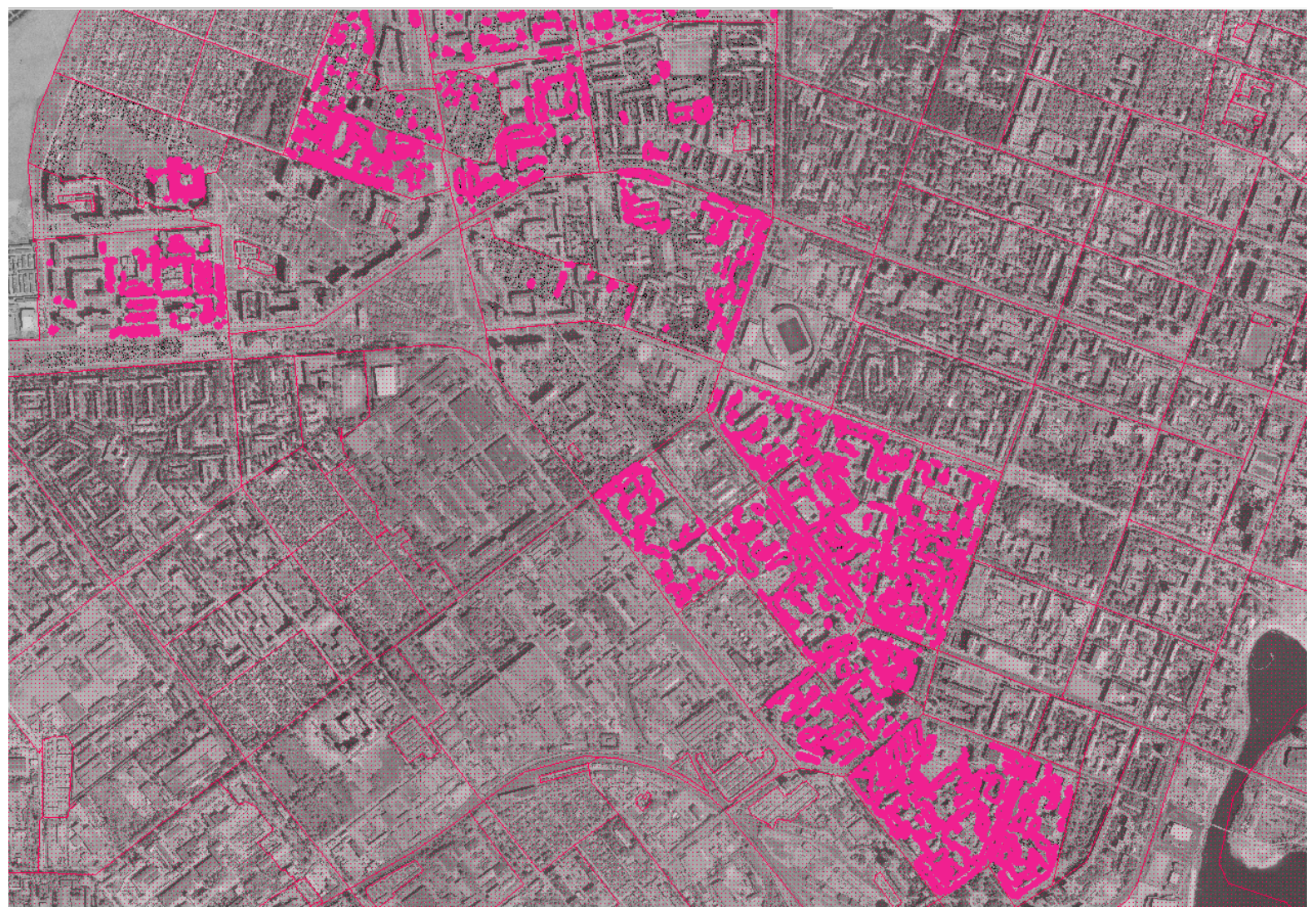

Рис. 1. Представление в ГИС «Карта 2011» кадастровых кварталов

с элементами растительного покрова

Газоны в городе Йошкар-Ола находятся под кустами и/или деревьями. Только в одном кадастровом квартале был выделен один элемент в виде газона. Поэтому элемент типа «газон» был исключен. В будущем нужно обратить внимание на те территории, на которых можно разбить, вместо беспорядочных тропинок, действительно ландшафтные газоны. Город Йошкар-Ола от этого стал бы красивее. Для этого нужно управлять тротуарами и всячески уменьшать площади под асфальтными покрытиями.

В 58 кадастровых кварталах с многоэтажными дамами (из общего количества 61 три квартала без растительности были исключены) были измерены 6141 земельных участков под древостоями и кустарниками. Затем суммированием определяли площади элементов растительного покрова (РП) для каждого кадастрового квартала. 
Приведены измеренные и расчетные данные по следующим параметрам подзоны, кадастрового квартала, элемента РП:

- количество элементов разного уровня $n_{\kappa}$, шт.;

- коэффициент абсолютной формы $s=S / P$;

- коэффициент относительной формы объекта $\gamma=100 S / P^{2}$.

В общем случае не волновая модель (тренд или детерминированная модель) содержит сумму двух биотехнических законов [1-8] в виде формулы

$$
\begin{array}{r}
y_{m}=y_{m 1}+y_{m 2}, \\
y_{m 1}=a_{1} x^{a_{2}} \exp \left(-a_{3} x^{a_{4}}\right), y_{m 2}=a_{5} x^{a_{6}} \exp \left(-a_{7} x^{a_{8}}\right),
\end{array}
$$

где $y_{m}$ - тренд; $x$ - объясняющая переменная; $a_{1} \ldots a_{8}$ - параметры модели в виде двухчленного тренда (1), определяемые в программной среде CurveExpert.

При этом каждый параметр модели (1) имеет физический смысл.

По 58 городским кадастровым кварталам данные приведены в таблице 1.

Таблица 1

Параметры кадастровых кварталов зоны многоэтажных жилых домов

\begin{tabular}{|c|c|c|c|c|c|c|c|c|c|c|c|}
\hline \multicolumn{6}{|c|}{$\begin{array}{c}\text { Параметры растительности } \\
\text { на кадастровых кварталах }\end{array}$} & \multicolumn{4}{|c|}{$\begin{array}{c}\text { Параметр формы элементов } \\
\text { растительного покрова }\end{array}$} & \multicolumn{2}{|c|}{\begin{tabular}{|c|} 
Активность \\
растительности
\end{tabular}} \\
\hline$R_{n}$ & $n_{p}$, шт. & $R_{P}$ & $P_{p}, \mathrm{M}$ & $R_{S}$ & $S_{p}, \mathrm{M}^{2}$ & $R_{a s}$ & $s_{p}, \mathrm{M}$ & $R_{\gamma}$ & $\gamma_{p}, \%$ & $R_{\mu}$ & $\mu_{p}$ \\
\hline 39 & 39 & 34 & 4009 & 20 & 18747 & 8 & 4.68 & 18 & 0.1166 & 14 & 16.50 \\
\hline 14 & 172 & 23 & 5851 & 34 & 11063 & 47 & 1.89 & 44 & 0.0323 & 21 & 13.78 \\
\hline 8 & 218 & 18 & 7013 & 33 & 11973 & 53 & 1.71 & 53 & 0.0243 & 28 & 11.13 \\
\hline 31 & 69 & 22 & 6374 & 8 & 28136 & 10 & 4.41 & 26 & 0.0693 & 10 & 17.87 \\
\hline$\ldots$ & $\ldots$ & $\ldots$ & $\ldots$ & $\ldots$ & $\ldots$ & $\ldots$ & $\ldots$ & $\ldots$ & $\ldots$ & $\ldots$ & $\ldots$ \\
\hline
\end{tabular}
с ранговыми местами по значениям параметров растительности

Зона застройки многоэтажными жилыми домами включает параметры растительного покрова по сумме всех элементов РП (знак $\uparrow$ показывает, что по вектору «лучше $\rightarrow$ хуже» рост значения параметра является предпочтительным):

$n_{p} \uparrow$ - численность элементов (газонов, кустарника, древостоев), шт.;

$P_{p} \uparrow$ - периметр всех элементов растительного покрова, м;

$S_{p} \uparrow$ - площадь земельных участков под элементами РП, ${ }^{2}$;

$s_{p} \uparrow$ - коэффициент абсолютной формы $s_{p}=S_{p} / P_{p}$ элементов РП;

$\gamma_{p} \uparrow-$ коэффициент относительной формы $\gamma_{p}=100 S_{p} / P_{p}^{2}$;

$\mu_{p} \uparrow$ - активность растительного покрова по сумме элементов. 
У любых факторов имеется векторная ориентация. Любой человек понимает направленность изменений, например, в сельском хозяйстве.

Каждый человек стремится к лучшему в жизни, поэтому возможны всего два варианта векторов поведения:

а) лучше меньше (да лучше, символ $\downarrow$ по вектору «лучше $\rightarrow$ хуже»);

б) лучше больше (и это благо для растительности, поэтому символ $\uparrow$ ).

В функции $=$ PAHГ $(\mathrm{N} 1 ; \mathrm{N} \$ 1: \mathrm{N} \$ 10 ; 0)$ для первого показателя $n_{p}$ в Excel приняты условные обозначения: N1 - идентификатор ранжируемого столбца и первой строки; $\mathrm{N} \$ 1$ - первая строка ранжируемого столбца; $\mathrm{N} \$ 58$ - последняя строка ранжируемого столбца по таблицt $1 ; 0 \vee 1$ - ранжирование по убыванию (0) или возрастанию (1).

Ранги изменяются от нуля, что лучше для идентификации экспоненциальных законов, поэтому придется из результатов ранжирования по местам в программной среде Excel вычитать единицу. Ранги удобнее вместо факторов, так как снимают математическую проблему «проклятия размерности», например, при рейтинге показателей.

Таким образом, факторный анализ проводится в четыре этапа:

1) выявление закономерностей рангового распределения;

2) рейтинг строк и столбцов матрицы по данным таблицы 1 ;

3) выявление закономерностей бинарных отношений;

4) рейтинг бинарных отношений по коэффициенту корреляции.

Ранговые распределения по принятому вектору предпорядка предпочтительности «лучше $\rightarrow$ хуже» у всех шести факторов одинаков: чем больше, тем лучше (рис. 2).

По этим шести параметрам городских кадастровых кварталов были получены уравнения ранговых распределений:

$$
\begin{gathered}
n_{p}=267,36986 \exp \left(-0,011193 R_{n}^{1,41014}\right) ; \\
P_{p}=16910,38 \exp \left(-0,12619 R_{p}{ }^{0,72280}\right) ; \\
S_{p}=90357,739 \exp \left(-0,34348 R_{S}{ }^{0,52913}\right) ; \\
s_{p}=6,13158 \exp \left(-0,042680 R_{a s}{ }^{0,85760}\right) ; \\
\gamma_{p}=5,35543 \exp \left(-0,77235 R_{\gamma}{ }^{0,56105}\right) ; \\
\mu_{p}=26,40801 \exp \left(-0,013630 R_{\mu}{ }^{1,29873}\right) .
\end{gathered}
$$

По ухудшению добротности измерений (снижению коэффициента корреляции) параметры растительности располагаются в порядке: 
1) 0,9967 - коэффициент относительной формы $\gamma_{p}$;

2) 0,9952 - численность элементов (кустарника, древостоев) $n_{p}$, шт.;

3) 0,9951 - коэффициент абсолютной формы элементов РП $s_{p}$;

4) 0,9870 - площадь земельных участков под элементами РП $S_{p}, \mathrm{~m}^{2}$;

5) 0,9837 - активность растительного покрова по всем элементов $\mu_{p}$;

6) 0,9673 - периметр всех элементов растительного покрова $P_{p}$, м.
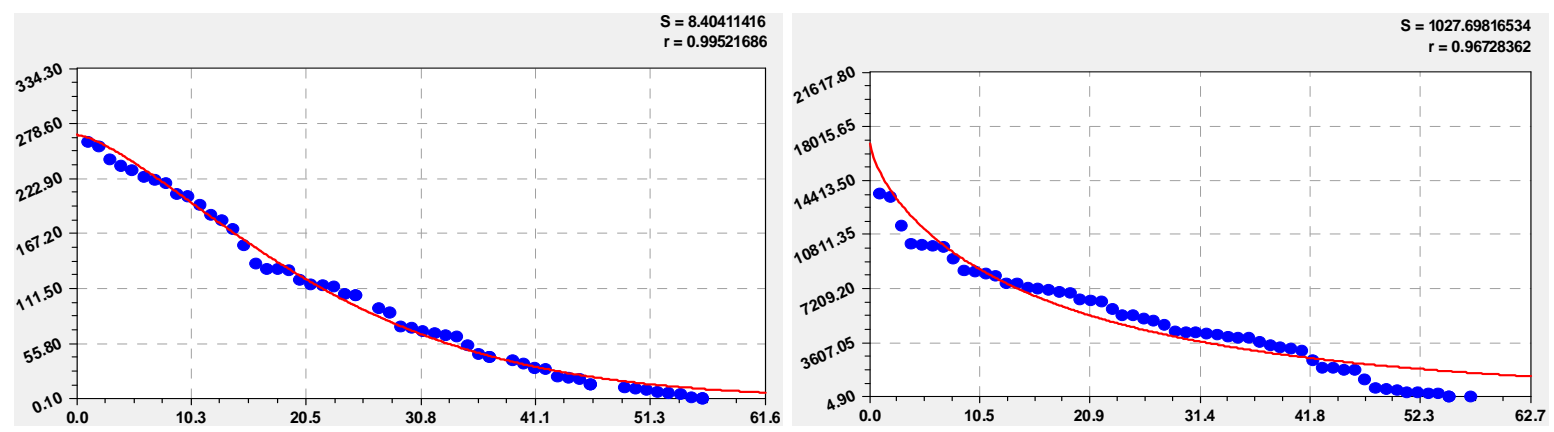

Численность элементов растительности

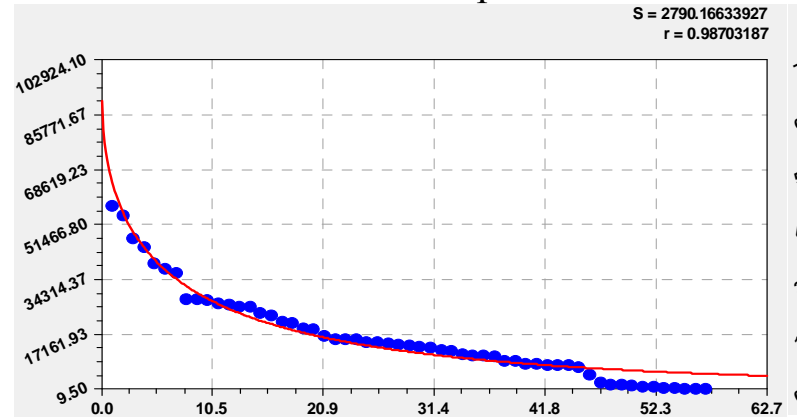

Периметр элементов растительности

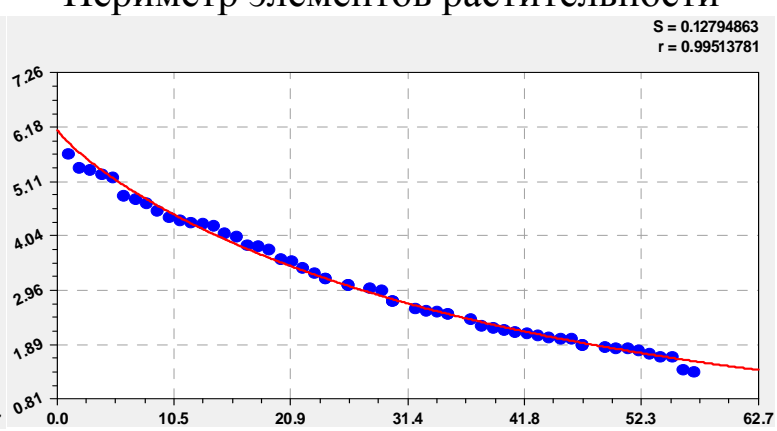

Площадь элементов растительности

Коэффициент абсолютной формы
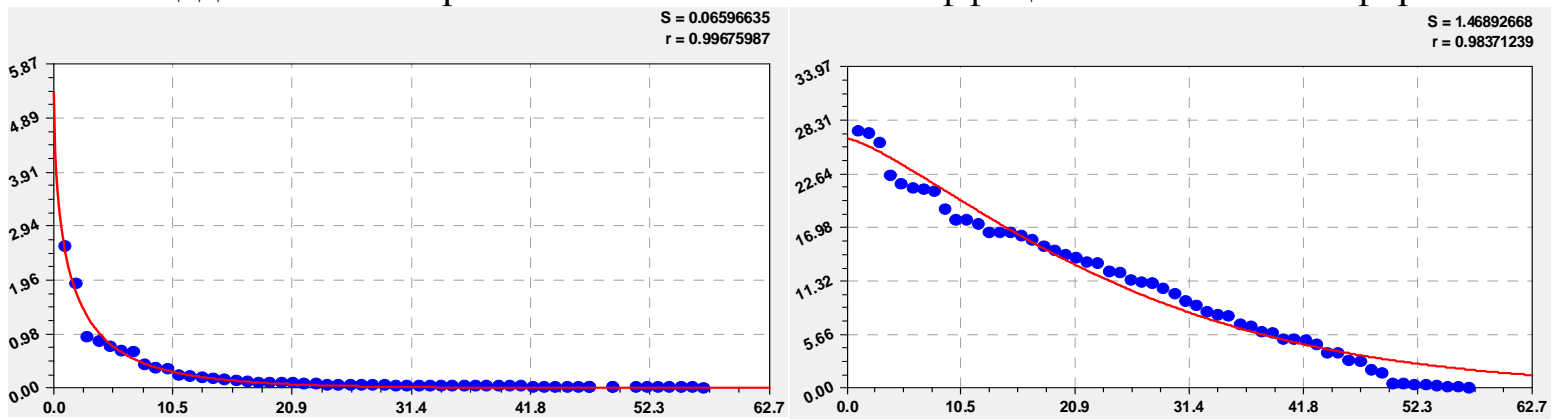

Коэффициент относительной формы

Активность растительного покрова

Рис. 2. Графики ранговых распределений параметров кадастровых кварталов

Наиболее точно получается коэффициент относительной формы, а с наибольшей погрешностью измеряется периметр элементов РП.

При этом все параметры имеют коэффициент корреляции более 0,95.

Без статистического моделирования, то есть без применения математических методов идентификации устойчивых законов, можно выявить значимость каждого из шести факторов, а также определить рейтинг среди 58 кадастровых кварталов, входя- 
щих в подзону 11 «Зона застройки многоэтажными жилыми домами».

Из данных таблицы 1 принимаем ранги параметров и поставим их в таблицу 2.

Таблица 2

Ранговые распределения параметров кадастровых кварталов зоны многоэтажных жилых домов

\begin{tabular}{|c|c|c|c|c|c|c|c|c|c|}
\hline $\begin{array}{l}\text { № } \\
\Pi / \Pi \\
\end{array}$ & \begin{tabular}{|c|} 
Код кадастрового квартала зоны \\
застройки многоэтажными жилыми домами \\
\end{tabular} & $R_{n}$ & $R_{P}$ & $R_{S}$ & $R_{a s}$ & $R_{\gamma}$ & $R_{\mu}$ & $\sum R$ & $I_{\kappa \varepsilon}$ \\
\hline & 12:05:0303001","',20110916,20110916,20120306,1,"",113638.3 & 39 & 34 & 20 & 8 & 18 & 14 & 133 & 18 \\
\hline 2 & 12:05:0702004","',20110916,20110916,20120306,1,"",80295.2 & 14 & 23 & 34 & 47 & 44 & 21 & 183 & 33 \\
\hline 3 & 12:05:0704005","',20110916,20110916,20120306,1,"',107571.1 & 8 & 18 & 33 & 53 & 53 & 28 & 193 & 38 \\
\hline & & & & & $\ldots$ & & & $\ldots$ & ... \\
\hline 21 & 12:05:0703003","',20110916,20110916,20120306,1,"',,303016.1 & 7 & $\mathbf{0}$ & $\mathbf{0}$ & 7 & 54 & $\mathbf{0}$ & 68 & 1 \\
\hline$\ldots$ & \begin{tabular}{|c} 
\\
$\ldots$ \\
\end{tabular} & $\ldots$ & $\ldots$ & $\ldots$ & $\ldots$ & $\ldots$ & $\ldots$ & $\ldots$ & $\ldots$ \\
\hline 57 & 12:05:0202004","",20110916,20110916,20120306,1,"',303214.2 & 3 & 4 & 9 & 30 & 49 & 31 & 126 & 15 \\
\hline 58 & 12:05:0203003","',20110916,20110916,20120306,1,"',238141.1 & 1 & 11 & 24 & 47 & 56 & 37 & 176 & 30 \\
\hline & Сумма рангов $\sum R$ & 1647 & 1652 & 1653 & 1648 & 1651 & 653 & 9904 & - \\
\hline & Рейтинговое место показателя & 1 & 4 & 5 & 2 & 3 & 5 & - & - \\
\hline
\end{tabular}

Приведение всех показателей к вектору «лучше $\rightarrow$ хуже» дает возможность суммирования всех рангов и по их сумме снова провести рейтинг.

Из данных таблицы 2 видно, что с экологических позиций самым лучшим (рис. 3) стал кадастровый квартал 0703003 (№21).

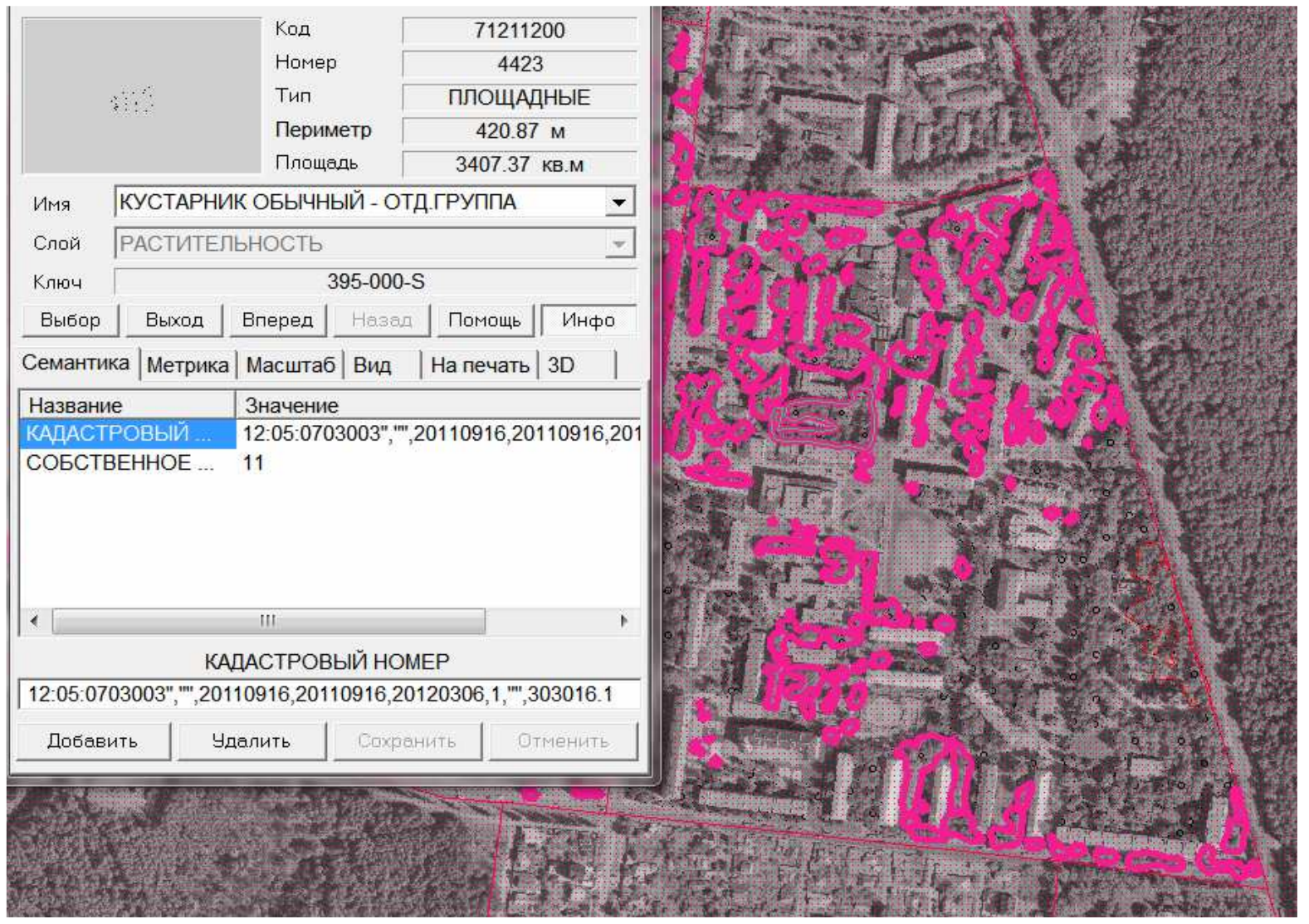

Рис. 3. Лучший с позиций зеленого города кадастровый квартал 
Определяем сумму рангов $\sum R$ и по росту этой суммы расставляем места рейтинга кадастровых кварталов. Первое место получил кадастровый квартал №21, а последнее 58-е место - кадастровый квартал №17, их физическое сопоставление даст список (систему) мер по дальнейшему улучшению экологического состояния города.

Далее проводим суммирование по всем 58 строкам и получаем рейтинг факторов.

Как показатель на первом месте оказалась численность элементов растительного покрова. Этот показатель очень прост в измерениях: нужно в наблюдениях отмечать метками и сосчитать количество площадок с газонами, кустарниками и деревьями.

Сумма рангов от рейтингового места (рис. 4) определяется формулой закона экспоненциального роста

$$
\sum R=62,74978 \exp \left(0,15297 I_{\kappa \varepsilon}^{0,55401}\right) .
$$

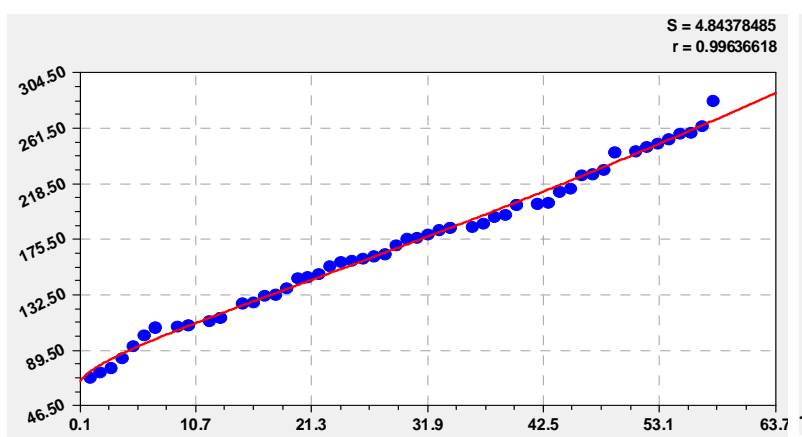

График рейтинга кадастровых кварталов

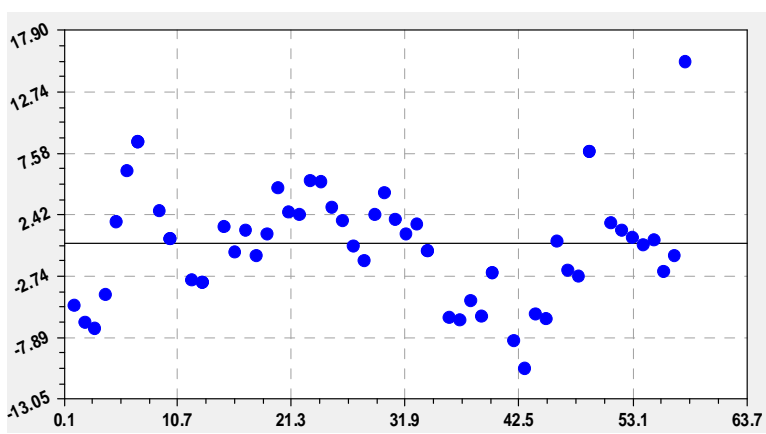

Остатки экспоненциального роста (8)

Рис. 4. Графики изменения суммы рангов кадастровых кварталов

Из уравнения (8) видно, что до идеала при условии $\sum R=0$, вместо 62,74798, еще очень далеко. Поэтому именно кадастровый квартал №21 должен быть спроектирован ландшафтными архитекторами для повышения всех шести показателей до общего нулевого ранга. При этом из остатков на рисунке 3 видно, что ранговое распределение происходит с колебательным возмущением.

Чем меньше уровень осознания администрацией города проблем и задач, стоящих перед ней, для создания зеленого города в будущем, тем больше амплитуда колебания и меньше период колебательного поведения системы управления городом.

Основные измерения элементов растительного покрова и выявленные закономерности позволили сформулировать следующие выводы:

1) по снижению коэффициента корреляции параметры растительности располагаются в порядке: 1) 0,9967 - коэффициент относительной формы $\gamma_{p}$;2) 0,9952 - численность элементов (кустарника, древостоев) $n_{p}$, шт.; 3) 0,9951 - коэффициент абсо- 
лютной формы элементов РП $s_{p}$; 4) 0,9870 - площадь земельных участков под элементами РП $S_{p}, \mathrm{M}^{2} ;$ 5) 0,9837 - активность растительного покрова по всем элементов $\mu_{p}$; 6) 0,9673 - периметр всех элементов растительного покрова $P_{p}$, м;

2) по росту этой суммы рангов первое место получил кадастровый квартал №21, a последнее 58-е место - кадастровый квартал №17; далее проводим суммирование по всем 58 строкам и получаем рейтинг факторов, как показатель на первом месте оказалась численность элементов РП;

3) среди влияющих переменных на первом месте оказалась площадь растительности на кадастровом квартале, на втором - периметр, как показатель на первом месте находится относительная форма, на втором - периметр элементов растительности.

Список литературы

1. Мазуркин, П. М. Агроэкологические зоны Тульской области / П. М. Мазуркин // Матер. конф. «Социально-эконом. и экологич. проблемы горной пром-ти, строительства и энергетики». 8-я Междунар. конф. по проблемам горной промышленности, строительства и энергетики. - Том 2. - Тула: ТулГУ, 2014. - С. 248-256.

2. Мазуркин, П. М. Биокаркас территории: учеб. пос. с грифом УМО РАЕ / П. М. Мазуркин. - Йошкар-Ола: Поволжский ГТУ, 2013. - 156 с.

3. Мазуркин, П. М. Динамика землепользования субъекта федерации / П. М. Мазуркин // Землеустройство и кадастры: проблемы и пути их решения. Матер. Междунар. науно-практ. конф. в рамках пленарного засед. Совета УМО вузов по образ. в области землеустройства и кадастров. - М.: ГУЗ, 2013. - С.94-99.

4. Мазуркин, П. М. Идентификация статистических устойчивых закономерностей / П. М. Мазуркин // Наука и мир: междунар. научн. ж-л. - 2013. - № 3(3). - С.28-33.

5. Мазуркин, П. М. Колебательное возмущение эргатической системы / П. М. Мазуркин // Фундаментальные исследования. - № 11 (часть 2). - 2013. - С.266-271.

6. Мазуркин, П. М. Коррелятивная вариация: учеб. пос. с грифомУМО РАЕ / П. М. Мазуркин. - Йошкар-Ола: Поволжский ГТУ, 2013. - 120 с.

7. Мазуркин, П. М. Прогноз землепользования в России / П. М. Мазуркин // Землеустройство и кадастр недвижимости: проблем и пути их решения. Матер. научнопракт форума, посв. 235-летию со дня основания Госуд. ун-та по землеустройству. - М.: ГУЗ, 2014. - С.61-67.

8. Мазуркин, П. М. Решение 23-ой проблемы Гильберта / П. М. Мазуркин // Междисципл. исследования в области математического моделирования и информатики. Матер. 3-й научно-прак. internet-конф. - Ульяновск: SIMJET, 2014. - C.269-277.

9. Панасанко С. Город - новая утопия, или горе от ума? 3 февраля 2015. URL: http://green-city.su/novaya-utopiya-ili-gore-ot-uma/ (Дата обращ. 18.02.2015).

10. G"unther Fischer, Harrij van Velthuizen, Mahendra Shah, Freddy Nachtergaele. Global Agro-ecological Assessment for Agriculture in the 21st Century: Methodology and Results. International Institute for Applied Systems Analysis, Laxenburg, Austria. Food and Agriculture Organization of the United Nations. Viale delle Terme di Caracalla. Rome, Italy, 2002. URL: http://webarchive.iiasa.ac.at/Research/LUC/SAEZ/index.html. 


\section{Bibliography}

1. Mazurkin, P. Agro-ecological zones of Tula region / PM Mazurkin // Mater. Conf. "Socio-Economy. and environmen. Mining issues prom-ty, builder-tion and energy. " 8th Int. Conf. on the problems of mining, construction and energy. - Volume 2 - Tula: Tula State University, 2014. - S. 248-256.

2. Mazurkin, P. Biokarkas territory: Proc. pos. stamped UMO PAE / PM Mazurkin. Yoshkar-Ola: Volga NTU, 2013. - 156 p.

3. Mazurkin, P. Dynamics Land federation subject / PM Ma zurkin // Land and inventories: problems and ways of solving them. Mater. Between-nar. nauno-practical. Conf. in the plenary sitting. Council of Association of universities in the image. in on-field land and inventories. - M .: GOOSE, 2013 - S.94-99.

4. Mazurkin, P. Identification of sustainable statistical regularities / PM Mazurkin // Science and peace: Intern. Scien. Well-liter. - 2013. - № 3 (3). - S.28-33.

5. Mazurkin, P. Oscillatory disturbances ergatic system / PM Ma zurkin // Basic Research. - № 11 (part 2). - 2013 - S.266-271.

6. Mazurkin, P. Correlative variation: Proc. pos. grifomUMO with PAE / PM Mazurkin. - Yoshkar-Ola: Volga NTU, 2013. - 120 p.

7. Mazurkin, P. Prediction of land use in Russia / PM Mazurkin // Terr-leustroystvo and cadastre of real estate: problems and ways of solving them. Mater. Scient Forum, dedicated. 235th anniversary of the founding Gosud. Univ of Land Management. - M .: GOOSE, 2014 S.61-67.

8. Mazurkin, P. Solution 23rd Hilbert problem / PM Mazurkin // Inter-distsipl. research in the field of mathematical modeling and computer science. Ma-ter. 3rd scientific and prac. internet-conf. - Ulyanovsk: SIMJET, 2014. - S.269-277.

9. Panasanko S. City - new utopia, or Woe from Wit? 3 February 2015. URL: http://green-city.su/novaya-utopiya-ili-gore-ot-uma/ (Date addressed. 18.2.2015).

10. G"unther Fischer, Harrij van Velthuizen, Mahendra Shah, Freddy Nachtergaele. Global Agro-ecological Assessment for Agriculture in the 21st Century: Methodology and Results. International Institute for Applied Systems Analysis, Laxenburg, Austria. Food and Agriculture Organization of the United Nations. Viale delle Terme di Caracalla. Rome, Italy, 2002. URL: http://webarchive.iiasa.ac.at/Research/LUC/SAEZ/index.html.

Салихов Мухаммет Габдухаевич, д-р техн. наук, профессор, кафедра автомобильных дорог Поволжского ГТУ. Телефон (8362) 68-60-72.

Царев Евгений Михайлович, д-р техн. наук, профессор, кафедра технологии и оборудования лесопромышленных производств ПГТУ. Телефон (8362) 68-60-57. 